\title{
Hepatitis C: crioglobulinemia y linfoma no-Hodgkin
}

\author{
M. Romero-Gómez y D. García-Romero \\ Unidad de Gestión Clínica de Enfermedades Digestivas. Hospital Universitario de Valme. Sevilla
}

\section{RESUMEN}

La infección por el virus de la hepatitis $C$ juega un papel principal en la patogénesis de la crioglobulinemia mixta, promoviendo la activación y expansión de las células B. Estos reajustes moleculares inducen la sintesis de crioglobulinas y la aparición de la vasculitis crioglobulinémica. El aclaramiento del virus provoca la resolución de las manifestaciones clínicas y de las alteraciones inmunológicas observados en la crioglobulinemia mixta en un alto porcentaje de los pacientes, pero no en todos. En algunos casos, la crioglobulinemia puede aparecer tras la respuesta virológica sostenida. Muchos mecanismos de la patogénesis de la crioglobulinemia mixta están fuertemente relacionados con la infección por VHC y, cuando el virus es eliminado, hay una mejoría en el curso de la enfermedad. Aun así, los pasos independientes relacionados con otros factores no mejoran tras la erradicación del virus.

En algunos tipos de linfomas no-Hodgkin de bajo grado (linfoma linfoplasmocítico y linfoma de la zona marginal) la respuesta sostenida tras el aclaramiento viral induce una remisión de la neoplasia. El VHC tiene un papel secundario en los linfomas agresivos y el aclaramiento del virus puede no inducir la remisión, pero puede disminuir la hepatotoxicidad asociada a la quimioterapia.

Por tanto, en la hepatitis C crónica, la combinación de interferón pegilado y ribavirina es altamente recomendable en el tratamiento de la crioglobulinemia mixta sintomática y los linfomas noHodgkin asociados al VHC.

Palabras clave: Hepatitis C. Crioglobulinemia. Linfoma noHodgkin.

\begin{abstract}
Hepatitis $\mathrm{C}$ virus infection plays a major role in the pathogenesis of mixed cryoglobulinemia, promoting activation and expansion of B cells. These molecular rearrangements induce synthesis of cryoglobulins and the appearance of cryoglobulinemic vasculitis. Clearance of the virus promotes resolution of the clinical manifestations and immunological disorders seen in mixed cryoglobulinemia in a large percentage of patients, but not in all. In some cases, cryoglobulinemia could appear after sustained response. Several steps in the pathogenesis of mixed cryoglobulinemia are strongly related to $\mathrm{HCV}$ infection and when the virus is eliminated, the disease course improves. However, independent steps related to other factors do not improve following viral clearance.

In some types of low-grade non-Hodgkin lymphoma (lymphomoplasmocytic lymphoma, marginal zone lymphoma) sustained response following antiviral treatment induces remission of the neoplasm. HCV has a minor role in aggressive lymphomas and clearance of the virus may not induce remission, but could decrease the hepatotoxicity associated with the chemotherapy.

Therefore, in chronic hepatitis $\mathrm{C}$, the combination of peginterferon + ribavirin is strongly recommended in treating symptomatic mixed cryoglobulinemia and HCV-related non-Hodgkin lymphomas.
\end{abstract}

Key words: Hepatitis C. Cryoglobulinemia. Non-Hodgkin lymphoma.
Correspondencia: Manuel Romero-Gómez. Unidad de Gestión Clínica de Enfermedades Digestivas. $2^{\text {a }}$ planta. Hospital Universitario de Valme. Ctra. de Cádiz s/n. 41014 Sevilla. e-mail: mromerog@supercable.es

\section{INTRODUCCIÓN}

Recientes estimaciones de la Organización Mundial de la Salud indican que 123 millones de personas están infectadas por el virus de la hepatitis C. Esta infección es responsable no sólo de producir hepatitis crónica que puede conducir a cirrosis, estadio final de la hepatopatía crónica y 
carcinoma hepatocelular, sino también de enfermedades extrahepáticas. El amplio rango de manifestaciones extrahepáticas sugiere que la hepatitis crónica por virus $\mathrm{C}$ podría ser considerada una enfermedad sistémica. Las manifestaciones extrahepáticas de la hepatitis $\mathrm{C}$ han sido clasificadas en cuatro categorías diferentes según la implicación de la infección crónica por virus $\mathrm{C}$ en la patogénesis. La crioglobulinemia mixta se debe mayoritariamente a la hepatitis $\mathrm{C}$ y el virus es el principal factor etiológico. El linfoma no-Hodgkin se ha relacionado con la infección por VHC, pero no se ha encontrado una relación patogénica. La hepatitis $\mathrm{C}$ se ha relacionado con la resistencia a la insulina y la diabetes mellitus tipo 2. Últimamente, se ha publicado una larga lista de observaciones anecdóticas pero el papel del virus de la hepatitis $\mathrm{C}$ aún debe ser demostrado.

A pesar de que muchos autores han explorado los mecanismos subyacentes del VHC en la producción de manifestaciones extrahepáticas, por el momento no está claro por qué algunos pacientes padecen únicamente de enfermedad hepática crónica mientras que otros desarrollan manifestaciones extrahepáticas de la enfermedad. El VHC es un virus ARN de cadena única. La existencia de reservorios extrahepáticos para la replicación del VHC permanece como una gran controversia. La replicación del ARN tiene lugar en diversos compartimentos del citoplasma celular y requiere proteínas tanto virales como del hospedador. Durante la replicación, el ARN genómico del VHC se transcribe en una cadena complementaria de ARN, proveyendo un molde para la síntesis del nuevo genoma viral. La presencia de una cadena negativa es esencial para demostrar replicación viral activa. En contraste con el virus de la inmunodeficiencia humana (VIH) y el virus de la hepatitis B (VHB), no existe forma intermedia de ADN ni tampoco forma estable nuclear. La implicación práctica de este hallazgo es que el aclaramiento viral sostenido es realmente posible. La infección por VHC podría inducir varias alteraciones inmunes desde la activación policlonal a monoclonal de las células B responsables de la crioglobulinemia mixta. En algunos casos la expansión monoclonal junto con varios reajustes moleculares, translocaciones cromosómicas y la sobreexpresión de bcl-2 podrían ser responsables del desarrollo de linfoma no-Hodgkin. Por tanto, el aclaramiento sostenido del VHC podría tener un impacto en la evolución clínica de aquellas enfermedades en cuya patogenia esté implicado el VHC.

\section{CRIOGLOBULINEMIA MIXTA Y HEPATITIS C}

La crioglobulinemia mixta (CM) es una vasculitis sistémica que afecta principalmente a los vasos pequeños $\mathrm{y}$, con menos frecuencia, a los medianos. La CM se caracteriza por la proliferación de clones de células $\mathrm{B}$ que producen el factor reumatoide IgM patogénico. Se han des- crito tres tipos de CM en base a los complejos de inmunoglobulinas hallados en el precipitado: el tipo I es una IgM monoclonal en el sitio de unión de la macroglobulinemia de Waldenstrom; el tipo II es un factor reumatoide IgM monoclonal junto con IgG policlonal; y el tipo III es un factor reumatoide IgM oligoclonal con IgG policlonal. La crioglobulinemia mixta (tipos II y III) ha sido fuertemente asociada a la hepatitis C. De una cohorte de 168 pacientes con crioglobulinemia, se observó que 155 (92\%) presentaban anti-VHC y, de estos, 152 (98\%) de los pacientes presentaban ARN del VHC (1). Los datos que apoyan el papel del VHC en la patogénesis de la $\mathrm{CM}$ incluyen: se ha encontrado anti-VHC en los precipitados policlonales IgG; el ARN del VHC está presente habitualmente en el crioprecipitado; y, por último, las crioglobulinas se observan más frecuentemente en pacientes con hepatitis $\mathrm{C}$ que en aquellos que presentan otras hepatopatías crónicas como la hepatitis B.

La patogénesis de la CM secundaria a VHC es compleja y parece comprender varios mecanismos (2). El VHC parece inducir la activación policlonal de las células B tras la interacción entre la proteína E2 y el receptor CD81. La activación de STAT3 por la proteína del core podría promover la expansión y modificaciones en la activación de células B causando la sobreexpresión de CD69, CD 71, CD86 e incremento de CXCR3 mayor de 5 veces, todo ello junto al descenso en la expresión de CXCR4. Estos eventos moleculares conducen a numerosas alteraciones inmunológicas responsables de la expansión monoclonal de crioglobulinas producidas por linfocitos $\mathrm{B}$ y alteraciones en la respuesta de linfocitos $\mathrm{T}$. Los pacientes con hepatitis $\mathrm{C}$ y crioglobulinemia mixta muestran un descenso en los linfocitos $\mathrm{T}$ reguladores tales como los CD5+(3). Además, la respuesta de Th1 está exacerbada con niveles mayores de TNF, INF- $\alpha$ e interleuquina-12, interleuquina-18 y descenso en las concentraciones de las interleuquinas de Th2, como la interleuquina-10 (4). Las alteraciones inmunológicas se corresponden con datos patológicos que demuestran infiltración neutrofílica con cambios leucocitoclásticos. La vasculitis clásica mediada por inmunocomplejos se encontró raramente, mientras que la presencia de infiltrado linfo-histocítico sugiere una patogénesis mediada por células $\mathrm{T}$, dejando a la inmunidad humoral un papel menor. Los niveles de ARN del VHC en los linfocitos circulantes obtenidos de pacientes con crioglobulinemia son mayores que los de aquellos pacientes sin crioglobulinemia, a pesar de que no existan diferencias en las concentraciones séricas de ARN del VHC. La cadena negativa del ARN viral se ha detectado en células mononucleares de sangre periférica de pacientes con crioglobulinemia, pero no en pacientes con hepatitis $\mathrm{C}$ crónica o aguda sin manifestaciones extrahepáticas (5). Estos datos apoyan la hipótesis de que el VHC infecta a los linfocitos B e induce cambios en la maduración de las células $\mathrm{B}$, promoviendo la producción de crioglobulinas. 
Existen escasos datos que analicen el papel de la hepatitis $\mathrm{C}$ en las manifestaciones de la crioglobulinemia. La solubilidad de las proteínas depende de la concentración, la temperatura, $\mathrm{pH}$, fuerza iónica de la solución y cambios en la superficie. Varios cambios han sido propuestos para explicar la producción de crioglobulinas en la presencia de hepatitis C: a) cambios en la estructura primaria de la porción variable de las inmunoglobulinas; b) reducción de la concentración de ácido siálico; y c) reducida cantidad de galactosa en la región Fc de las inmunoglobulinas (6).

Las principales manifestaciones clínicas son púrpura, artralgias, astenia y afectación renal o neurológica. La crioglobulinemia se ha relacionado con progresión hacia la esteatosis y la fibrosis en la hepatitis C (7), y las crioglobulinas se han observado más frecuentemente en pacientes cirróticos. En un metaanálisis de 19 estudios y 2.323 pacientes, se encontró asociación entre crioglobulinemia y cirrosis tras ajustar por edad, género y duración estimada de la enfermedad (8). Las crioglobulinas específicas juegan un papel en el desarrollo de las lesiones de la glomerulonefritis membranosa proliferativa y lesiones dérmicas (9), pero por ahora no se ha demostrado su implicación en la progresión de la fibrosis hepática. Las crioglobulinas también pueden ser meros marcadores de la cirrosis avanzada, como ha sido comunicado para los anticuerpos antifosfolípidos (10).

La historia natural de la crioglobulinemia fue descrita por Ferri y colaboradores (1) y Sene y colaboradores (11) en varias cohortes numerosas. Los estudios indicaban que, desde un punto de vista clínico, la púrpura ocurría en el $40-81 \%$, artralgias en $43-72 \%$ y debilidad en $80 \%$. La neuropatía periférica estaba presente en el $47-58 \%$ y la afectación renal en el 10-20\% de los casos. A pesar de que no se hayan comunicado grandes diferencias entre pacientes con hepatitis $\mathrm{C}$ con y sin crioglobulinemia mixta, existían más mujeres mayores con un mayor tiempo de infección de la primera, además de presentar ligeramente con más frecuencia genotipos 2 y 3 . Los factores epidemiológicos de los pacientes con crioglobulinemia mixta secundaria a virus $\mathrm{C}$ fueron similares a los de los pacientes con hepatitis $\mathrm{C}$ sin crioglobulinemia, con respecto a la distribución genotípica y al estadio de fibrosis. Niveles bajos de C4 y CH50 junto con elevación o normalidad en los niveles de C3 se observaron en la mayoría de los casos. Las principales causas de muerte fueron la afectación renal en el 33\%, el estadio final de enfermedad hepática en el 13\%, linfoma de células B en el 13\%, carcinoma hepatocelular en el $10 \%$ y un $30 \%$ de causas misceláneas. La causa de muerte fue secundaria a la $\mathrm{CM}$ en el $64 \%$ de los casos, "posiblemente relacionada" en el $13 \%$ y "no relacionada" en el $23 \%$. Como factores independientes de mortalidad encontraron la edad mayor de 60 años, género femenino y afectación renal. Los factores asociados con la crioglubulinemia mixta sintomática y peor pronóstico fueron la edad al diagnóstico, niveles séricos de crioglobulinas al diagnóstico, duración de la infección por VHC y el tipo de crioglobulinemia (siendo la tipo II la de peor pronóstico) (41). Aun así, durante el seguimiento más del $40 \%$ de los casos presentaban alteraciones en las características de los criocritos y, por tanto, del tipo de crioglobulinemia mixta. Menos del $60 \%$ de los pacientes diagnosticados como CM tipo III cambiaron a tipo II.

El efecto del aclaramiento de VHC en la crioglobulinemia ha sido valorado desde diferentes puntos de vista. Puesto que la crioglobulinemia mixta es una enfermedad inmune secundaria a la infección crónica por VHC, el objetivo principal del tratamiento de esta entidad se centra en la erradicación viral. El impacto de la respuesta viral sostenida en la crioglobulinemia podría ser enfocado asegurando varios aspectos como aminorar las manifestaciones clínicas de la enfermedad y evitando las complicaciones que atenten contra la vida del paciente, así como revertir la degeneración inmunológica que producen las crioglobulinas. En la mayoría de los pacientes, el alcanzar la respuesta viral sostenida se asocia con una mejoría en las manifestaciones clínicas de la enfermedad tales como púrpura, artralgia o debilidad, y un descenso en el nivel de criocrito hasta ser inferior al nivel de detección. La reaparición del ARN del VHC en los pacientes recidivantes se acompaña, en la mayoría de los casos, de recidiva de la vasculitis por crioglobulinemia mixta. De todos modos, el desarrollo de crioglobulinemia subsiguiente al aclaramiento del virus ha sido registrado en respondedores sostenidos sin crioglobulinas de base (12). Este hecho no se comprende en su totalidad. Podría explicarse como una consecuencia de la persistencia de reservorios virales que pudiera suponer una continua expansión de células B; la producción de crioglobulinas podría llegar a ser un proceso autónomo, siguiendo el aclaramiento del VHC, o podría ser un efecto adverso inmunológico a la administración de interferón pegilado o ribavirina.

El tratamiento de primera línea en la crioglobulinemia mixta es el tratamiento antiviral. No obstante, en pacientes con afectación renal, neuropatía severa y complicaciones vitales, es preciso utilizar varias drogas inmunosupresoras (corticosteroides, ciclofosfamida o azatrioprina) o plasmaféresis antes o en combinación con el tratamiento antiviral. Se ha observado que la respuesta virológica sostenida aumentaba en pacientes tratados con interferón pegilado + ribavirina en comparación con aquellos pacientes que sólo recibieron interferón o la pauta estándar de interferón + ribavirina (Fig. 1).

Los pacientes con crioglobulinemia mixta tratados con interferón pegilado + ribavirina demostraron un amplio rango de respuesta viral sostenida entre el 44 y el $58 \%$, dependiendo de la distribución de los genotipos y la dosis de peg-interferón alfa $2 \mathrm{~b}$ administrada. La dosis de interferón pegilado de $1 \mu \mathrm{g} / \mathrm{kg} / \mathrm{semana}$ parece conducir a una mayor tasa de respuesta que la dosis completa de $1,5 \mu \mathrm{g} / \mathrm{kg} / \mathrm{sema}-$ na (13). El criocrito desapareció en el 30- 96\%, y la respuesta clínica se obtuvo en el 62,5-89\% de los casos. En los respondedores sostenidos, el criocrito decreció desde $1,1 \pm 1,2$ hasta $0,1 \pm 0,2 \mathrm{~g} / \mathrm{l} ; \mathrm{p}<0,001$ y la proteinuria des- 


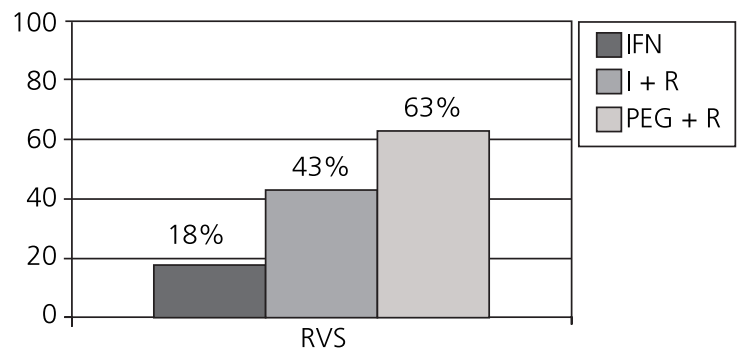

Fig. 1. Respuesta virológica sostenida en pacientes con hepatitis $C$ crónica y crioglobulinemia mixta. Como puede observarse, en pacientes sin crioglobulinemia, peginterferón + ribavirina es la mejor opción disponible para su tratamiento. RVS: respuesta virológica sostenida; IFN: interferón solo; I + R: interferón estándar + ribavirina; PEG + R: peginterferón alfa + ribavirina. Datos extraídos de las referencias 13, 15 y 17.

de 4,4 $\pm 2,3$ hasta $0,6 \pm 0,9 \mathrm{~g} / \mathrm{d} ; \mathrm{p}=0,002$ pero, en los no respondedores, el criocrito también disminuyó desde $1 \pm$ 1,5 hasta $0,5 \pm 0,9 \mathrm{~g} / 1 ; \mathrm{p}=0,002$ y la proteinuria descendió desde 4,1 $\pm 3,2$ hasta $2,2 \pm 3,1 ; p=n s$. La respuesta virológica sostenida se consiguió en poco menos de dos tercios de los pacientes $(62,5 \%)$, la desaparición de las crioglobulinas en algo más de la mitad de los pacientes $(57,5 \%)$ y la remisión clínica se observó en el $62,5 \%$ (Fig. 2) (14). Aunque la terapia antiviral parece ser de utilidad en el manejo de las enfermedades renales en pacientes con crioglobulinemia mixta, no se ha observado influencia en los niveles séricos de creatinina, la tasa de filtración glomerular y las lesiones glomerulares, incluso

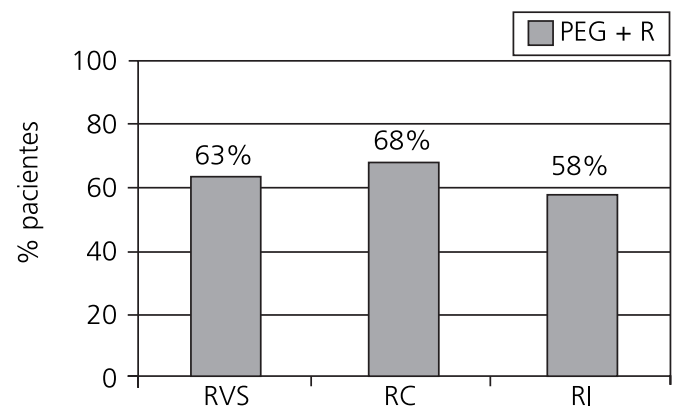

Fig. 2. Respuesta virológica, clínica e inmunológica a peginterferón + ribavirina en pacientes con hepatitis C crónica y crioglobulinemia. RVS: respuesta virológica sostenida; RC: respuesta clínica; Rl: respuesta inmunológica. Datos extraídos de la referencia 14. en los respondedores sostenidos. El aclaramiento viral mejora la enfermedad renal, principalmente debido a la supresión de la estimulación de linfocitos B y la producción de crioglobulinas. Aun así, el depósito persistente de inmunocomplejos provoca daño y esclerosis y, por tanto, los pacientes deberían recibir tratamiento precoz para evitar las lesiones renales irreversibles. En una cohorte de 18 pacientes con nefropatía por CM tratados con interferón estándar $(\mathrm{n}=14)$ o pegilado $(\mathrm{n}=4)$ más ribavirina la tasa de respuesta viral sostenida fue del $67 \%$, a pesar de que la mitad de los pacientes estuviesen afectados por genotipo 1. Además, las crioglobulinas desaparecieron en 5 de 12 respondedores, pero en ninguno de los no respondedores (15). Por último, la neuropatía periférica de leve a moderada mejora, o desaparece, tras el aclaramiento viral en más de dos tercios de los casos. A pesar de esto, los casos graves muestran una tasa de respuesta muy baja.

La tolerabilidad y la tasa de respuesta viral sostenida debería ser similar en pacientes con hepatitis C crónica con y sin crioglobulinemia (16). De hecho, tal como se ha documentado en los pacientes sin crioglobulinas, los factores asociados a la respuesta sostenida en pacientes con crioglobulinemia mixta fueron los genotipos 2 ó 3, de edad menor de 50 años, con baja carga viral, de etnia no afroamericana y de género femenino (17). En la mayor cohorte estudiada, la variable independiente asociada con respuesta sostenida fue la ausencia de insuficiencia renal. Cuando la tasa de filtración glomerular era menor de 70 $\mathrm{ml} / \mathrm{min}$, la tasa de respuesta clínica completa fue de una quinta parte, en comparación con los pacientes sin afectación renal (14).

\section{LINFOMA NO-HODGKIN EN LA HEPATITIS C CRÓNICA}

La hepatitis $\mathrm{C}$ parece estar estrechamente relacionada con el linfoma no-Hodgkin (LNH) en algunos países, pero no en otros. En Italia, la prevalencia de hepatitis $\mathrm{C}$ en pacientes con LNH se encuentra entre el 8,9 y el $37,1 \%$ con una media del $19,8 \%$ en una cohorte de 2.668 casos procedentes de 18 estudios. Contrariamente, en más de 300 casos de LNH en el norte de Europa, ningún paciente mostraba anticuerpos anti-VHC. No se observó asociación en 2 estudios de Canadá, pero en EE.UU. la asociación dependía del Estado. En Japón, la prevalencia de hepatitis $\mathrm{C}$ variaba entre el 5,7 y el 22,2\% con una media del $11,3 \%$. Matsuo y cols. (18) encontraron que la prevalencia de hepatitis $\mathrm{C}$ estaba incrementada al menos 5 veces en los pacientes con linfoma no-Hodgkin. Un metaanálisis que incluyó 48 estudios concluyó que la prevalencia de VHC en los pacientes con LNH de células B era del 15\%; mucho mayor que en la población general (sobre $1,5 \%$ ) y que en los pacientes con otras patologías hematológicas $(2,9 \%)$, sugiriendo que el VHC tenía un papel etiológico en el LNH (19). A pesar de la variabilidad de la prevalencia de hepatitis $\mathrm{C}$, parece que el riesgo 
relativo de LNH en pacientes con hepatitis C crónica es entre 2 y 4 veces mayor que en los sujetos no infectados; al menos en los pacientes de Japón o de la región mediterránea, pero no en el caso de Norteamérica y Europa del Norte (20). Estos datos sugieren que la inducción de LNH relacionada con VHC emerge de la interacción de factores ambientales y genéticos. Los polimorfismos de la IL-10 (como el 1082GG) guardan relación con el incremento en la producción de IL-10, y con un mayor riesgo de desarrollar linfoma no-Hodgkin en pacientes con hepatitis $\mathrm{C}$ crónica comparado con aquellos con hepatitis $\mathrm{C}$ sin linfoma, o con linfoma no-Hodgkin sin infección por VHC (21).

La linfomagénesis inducida por VHC parece empezar con procesos mediados por el antígeno de VHC que inducen una activación policlonal de las células B siguiendo a la interacción entre la proteína E2 y el receptor CD81; la activación de STAT3 por la proteína del core provoca la expansión y modificaciones en la activación de células B. Estos fenómenos moleculares conducen a la expansión monoclonal, translocación cromosómica [t (14:18)], la sobreexpresión de bcl-2 y, finalmente, al linfoma de células B. A pesar de que el ARN del VHC se replique sin ADN intermediario sin ser integrado en el genoma de la célula hospedadora, el virus $\mathrm{C}$ podría producir malignidad por otros mecanismos como la activación de oncogenes, la inducción al crecimiento celular y la inhibición de la apoptosis (22). Existe evidencia creciente que apoya un posible papel de agentes infecciosos en el desarrollo de varias neoplasias como el virus de Epstein-Barr en el linfoma tipo Burkitt, parvovirus 19 en la aplasia pura de células rojas, Helicobacter pylori en el linfoma tipo MALT de células B y el herpes virus humano en el sarcoma de Kaposi.

El linfoma no-Hodgkin en pacientes con hepatitis C crónica debería clasificarse en dos grupos: desarrollo de linfoma en pacientes con crioglobulinemia mixta y formas idiopáticas. Se observó linfoma no-Hodgkin en el 5$15 \%$ de casos de crioglobulinemia mixta asociada a hepatitis C (23-25). Además, la incidencia de linfoma en pacientes con CM es mayor de 35 veces lo esperado en la población normal. Los tipos histológicos de linfomas presentes en la crioglobulinemia mixta son principalmente linfomas no agresivos e incluyen: linfoma linfoplasmocítico, linfoma de la zona marginal [nodal, esplénico y extranodal (forma MALT)], leucemia linfocítica crónica de estirpe B y linfoma folicular. En pacientes con hepatitis C sin crioglobulinemia mixta, la incidencia de linfoma B de células grandes de alto grado y linfoma folicular fue mayor que en los pacientes con crioglobulinemia y similares a la de los pacientes no infectados por VHC $(26,27)$ (Tabla I).

El pronóstico de los linfomas B difusos de células grandes asociados a la hepatitis $\mathrm{C}$ es peor que el de los linfomas no asociados a hepatitis C. Una cohorte de 26 casos de LNH asociado con hepatitis C se comparó con casos de pacientes sin infección por VHC. La transformación de linfomas de bajo grado a linfomas difusos de células B grandes fue más frecuente en pacientes positivos para VHC (32\%) que en los negativos (6\%). Además, la afectación esplénica se observó más frecuentemente en pacientes positivos para VHC. Los pacientes con hepatitis $\mathrm{C}$ y linfoma difuso de células grandes de estirpe B mostraron menos supervivencia media y, a los dos años, la tasa de supervivencia fue del $56 \%$ en los individuos VHC positivo frente al $80 \%$ en los VHC negativos. Más aún, la hepatotoxicidad se presentó más frecuentemente en los pacientes VHC positivos, apareciendo en dos tercios de los casos (15 de 23 pacientes) (28). Por tanto, la hepatitis $\mathrm{C}$ tiene una influencia negativa en la historia natural del linfoma no-Hodgkin.

Los linfomas más claramente vinculados a la hepatitis C incluyen: linfoma linfoplasmocítico y linfomas de la zona marginal. El linfoma esplénico con tricolinfocitos es una alteración crónica linfoproliferativa de células B histológicamente indistinguible, en el bazo y la médula ósea, del linfoma esplénico de la zona marginal (29). Existe una evidencia creciente, en ciertos linfomas de bajo grado de estirpe $\mathrm{B}$, de que el tratamiento de la hepatitis $C$ con terapia antiviral combinada como el interferón pegilado y la ribavirina puede conducir a la remisión del linfoma. El linfoma esplénico con tricolinfocitos asociado con hepatitis $\mathrm{C}$ y crioglobulinemia mixta regresa tras el tratamiento efectivo con terapia antiviral en más del $80 \%$ de los casos (30). En la mayor cohorte estudiada, 18 casos fueron tratados con interferón (es-

Tabla I. Porcentaje de subtipos de LNH-B en pacientes con hepatitis y crioglobulinemia y pacientes con hepatitis C y crioglobulinemia en comparación con el estudio internacional del linfoma

\begin{tabular}{lccc}
\hline Tipo de linfoma & VHC-crioglobulinemia & VHC-no crioglobulinemia & Estudio internacional del linfoma \\
\hline Linfoplasmático & $33 \%$ & $5 \%$ & $1,2 \%$ \\
MZL: nodal & $13 \%$ & $3 \%$ & $1,8 \%$ \\
MZL: esplénico & $5 \%$ & $2 \%$ & $<1 \%$ \\
MZL: extranodal & $9 \%$ & $42 \%$ & $7,6 \%$ \\
Folicular & $12 \%$ & $20 \%$ & $22,1 \%$ \\
Célula B grande difusa & $25 \%$ & $26 \%$ & $30,6 \%$ \\
Pacientes con LNH-B (n) & 137 & 85 & 1.069 \\
\hline
\end{tabular}


tándar o pegilado) + ribavirina. Se observó respuesta viral sostenida en 14 de $18(77,8 \%)$ y esta estaba asociada a respuesta hematológica. De los 4 pacientes no respondedores, la respuesta hematológica fue completa en 2 y parcial en los otros 2 casos (31). Aun así, a pesar de la respuesta completa hematológica y viral, persistió la realineación genética de las inmunoglobulinas monoclonales. Estos hallazgos contrastan con informes previos en los que la desaparición de los clones de células B se observó frecuentemente tras la erradicación viral, al menos en los pacientes con hepatitis $C$ crónica, con o sin crioglobulinemia. Esta discrepancia podría reflejar las diferencias en la carga tumoral o en los requerimientos de supervivencia. En los linfomas esplénicos sin tricoleucocitos, algunos clones pueden sobrevivir incluso tras la erradicación efectiva del virus C (32). La respuesta hematológica se ha informado como estable durante muchos años tras el aclaramiento del virus.

En los linfomas no-Hodgkin de bajo grado fuertemente relacionados con la hepatitis $\mathrm{C}$ y la crioglobulinemia mixta, tales como los inmunocitomas linfoplasmocíticos, se ha logrado la remisión completa de linfoma tras lograr el aclaramiento viral (33). Más aún, los linfomas de la zona marginal incluyendo los casos extranodales como el linfoma tipo MALT gástrico, duodenal o ileal alcanzaron la remisión completa cuando la hepatitis $\mathrm{C}$ asociada fue resuelta. Por tanto, la infección por VHC juega un papel en el desarrollo del linfoma MALT similar al del Helicobacter pylori y, en algunas circunstancias, una acción sinérgica entre ambas entidades podría promover linfomas extranodales de bajo grado (34). Por último, la erradicación del VHC se ha implicado en la remisión de los linfomas natural killer hepáticos, a pesar de que este linfoma pertenezca a una forma agresiva (35). También se ha informado de la regresión de linfomas marginales no esplénicos en estadio avanzado, tras el tratamiento de la hepatitis C (36). En una cohorte de 12 pacientes con linfoma no-Hodgkin de bajo grado asociado a hepatitis $\mathrm{C}$, el tratamiento antiviral obtuvo la remisión completa en 7 pacientes, respuesta parcial en 2 , enfermedad estable en 2 y enfermedad progresiva en 1 paciente. La remisión del linfoma se correlacionó al aclaramiento viral. Ninguno de los no respondedores presentó respuesta hematológica. La tolerancia de la combinación interferón pegilado + ribavirina fue bastante similar a la comunicada en pacientes con hepatitis $\mathrm{C}$ sin enfermedades malignas (37).

La linfomagénesis es un proceso multifactorial y la hepatitis $\mathrm{C}$ parece jugar un papel importante en algunos tipos de linfoma, en los cuales, la erradicación precoz del virus produce la regresión tumoral (38). De todos modos, los linfomas agresivos están raramente asociados a hepatitis $\mathrm{C}$ y el tratamiento antiviral no influye en la tasa de remisión. No obstante, el aclaramiento del virus reduce la tasa de hepatotoxicidad asociada a la quimioterapia $(39,40)$. Por esta razón es necesario un enfoque multidisciplinar en el manejo clínico de estos pacientes.

\section{BIBLIOGRAFÍA}

1. Ferri C, Sebastiani M, Giuggioli D, Cazzato M, Longombardo G, Antonelli A, et al. Mixed cryoglobulinemia: Demographic, clinical, and serologic features and survival in 231 patients. Semin Arthritis Rheum 2004; 33: 355-74.

2. Sansonno D, Tucci FA, Lauletta G, De Re V, Montrone M, Troiani $\mathrm{L}$, et al. Hepatitis $\mathrm{C}$ virus productive infection in mononuclear cells from patients with cryoglobulinaemia. Clin Exp Immunol 2007; 147: 241-8.

3. Boyer O, Saadoun D, Abriol J, Dodille M, Piette JC, Cacoub P, et al $\mathrm{CD} 4+\mathrm{CD} 25+$ regulatory T-cell deficiency in patients with hepatitis C-mixed cryoglobulinemia vasculitis. Blood 2004; 103: 3428-30.

4. Loffreda S, Muratori P, Muratori L, Mele L, Bianchi FB, Lenzi M. Enhanced monocyte Th1 cytokine production in HCV-infected cryoglobulinemic patients. J Hepatol 2003; 38: 230-6.

5. Sansonno D, Lauletta G, Montrone M, Tucci FA, Nisi L, Dammacco F. Virological analysis and phenotypic characterization of peripheral blood lymphocytes of hepatitis $\mathrm{C}$ virus-infected patients with and without mixed cryoglobulinaemia. Clin Exp Immunol 2006; 143: 288-96.

6. Lawson EQ, Brandau DT, Trautman PA, Middaugh CR. Electrostatic properties of cryoimmunoglobulins. J Immunol 1988; 140: 1218-22.

7. Saadoun D, Asselah T, Resche-Rigon M, Charlotte F, Bedossa P, Valla D, et al. Cryoglobulinemia is associated with steatosis and fibrosis in chronic hepatitis C. Hepatol 2006; 43: 1337-45.

8. Kayali Z, Buckwold VE, Zimmerman B, Schmidt WN. Hepatitis C, cryoglobulinemia, and cirrhosis: A meta-analysis. Hepatol 2002; 36 (4 Pt 1): 978-85.

9. Musset L, Diemert MC, Taibi F, Thi Huong Du L, Cacoub P, Leger JM, et al. Characterization of cryoglobulins by mmunoblotting. Clin Chem 1992; 38 (6): 798-802.

10. Romero Gómez M, López Lacomba D, García-Díaz E, Guil A, Gutiérrez R, Otero MA, et al. Prevalence and clinical significance of antiphospholipid antibodies in chronic hepatitis C. Med Clin (Barc) 2000; 114: 367-70.

11. Sene D, Ghillani-Dalbin P, Thibault V, Guis L, Musset L, Duhaut P, et al. Longterm course of mixed cryoglobulinemia in patients infected with hepatitis C virus. J Rheumatol 2004; 31: 2199-206.

12. D'Amico E, Chincoli C, Cacciatore P, di Pasqua G, Cosentino L, Riario-Sforza G, et al. Effects of combined antiviral therapy on asymptomatic mixed cryoglobulinemia in naive patients with chronic hepatitis C virus infection: A preliminary study. Dig Dis Sci 2005; 50: 2344-7.

13. Mazzaro C, Zorat F, Caizzi M, Donada C, Di Gennaro G, Maso LD, et al. Treatment with peg-interferon alfa-2b and ribavirin of hepatitis C virus-associated mixed cryoglobulinemia: A pilot study. J Hepatol 2005; 42: 632-8.

14. Saadoun D, Resche-Rigon M, Thibault V, Piette JC, Cacoub P. Antiviral therapy for hepatitis $\mathrm{C}$ virus -associated mixed cryoglobulinemia vasculitis: A long-term follow up study. Arthritis Rheum 2006; 54: 3696-706

15. Rossi P, Bertani T, Baio P, Caldara R, Luliri P, Tengattini F, et al Hepatitis C virus-related cryoglobulinemic glomerulonephritis: Long-term remission after antiviral therapy. Kidney Int 2003; 63: 2236-41

16. Calleja JL, Albillos A, Moreno-Otero R, Rossi I, Cacho G, Domper F, et al. Sustained response to interferon-alpha or to interferon-alpha plus ribavirin in hepatitis $\mathrm{C}$ virus-associated symptomatic mixed cryoglobulinaemia. Aliment Pharmacol Ther 1999; 13: 1179-86.

17. Kayali Z, Labrecque DR, Schmidt WN. Treatment of hepatitis C cryoglobulinemia: Mission and challenges. Curr Treat Options Gastroenterol 2006; 9: 497-507.

18. Matsuo K, Kusano A, Sugumar A, Nakamura S, Tajima K, Mueller NE. Effect of hepatitis C virus infection on the risk of non-Hodgkin's lymphoma: A meta-analysis of epidemiological studies. Cancer Sci 2004; 95: 745-52.

19. Gisbert JP, García-Buey L, Pajares JM, Moreno-Otero R. Prevalence of hepatitis $C$ virus infection in B-cell non-Hodgkin's lymphoma: Systematic review and meta-analysis. Gastroenterol 2003; 125: 1723-32.

20. Mazzaro C, Tirelli U, Pozzato G. Hepatitis C virus and non-Hodgkin's lymphoma 10 years later. Dig Liver Dis 2005; 37: 219-26. 
21. Persico M, Capasso M, Persico E, Masarone M, Renzo A, Spano D, et al. Interleukin-10. $1082 \mathrm{GG}$ polymorphism influences the occurrence and the clinical characteristics of hepatitis $\mathrm{C}$ virus infection. J Hepatol 2006; 45: 779-85.

22. Morris JD, Eddleston AL, Crook T. Viral infection and cancer. Lancet 1995; 346: 754-8.

23. La Civita L, Zignego AL, Monti M, Longombardo G, Pasero G, Ferri C. Mixed cryoglobulinemia as a possible preneoplastic disorder. Arthritis Rheum 1995; 38: 1859-60.

24. Monti G, Pioltelli P, Saccardo F, Campanini M, Candela M, Cavallero $\mathrm{G}$, et al. Incidence and characteristics of non-Hodgkin lymphomas in a multicenter case file of patients with hepatitis $C$ virus-related symptomatic mixed cryoglobulinemias. Arch Intern Med 2005; 165: 101-5.

25. Saadoun D, Sellam J, Ghillani-Dalbin P, Crecel R, Piette JC, Cacoub $\mathrm{P}$. Increased risks of lymphoma and death among patients with nonhepatitis C virus-related mixed cryoglobulinemia. Arch Intern Med 2006; 166: 2101-8.

26. Pioltelli P, Gargantini L, Cassi E, Santoleri L, Bellati G, Magliano $\mathrm{EM}$, et al. Hepatitis C virus in non-Hodgkin's lymphoma. A reappraisal after a prospective case-control study of 300 patients. Lombart Study Group of HCV-Lymphoma. Am J Hematol 2000; 64: 95-100.

27. Agnello V, De Rosa FG. Extrahepatic disease manifestations of HCV infection: Some current issues. J Hepatol 2004; 40: 341-52.

28. Besson C, Canioni D, Lepage E, Pol S, Morel P, Lederlin P, et al. Groupe d'Etude des Lymphomes de l'Adulte Programs. Characteristics and outcome of diffuse large B-cell lymphoma in hepatitis C virus-positive patients in LNH 93 and LNH 98. Groupe d'Etude des Lymphomes de l'Adulte programs. J Clin Oncol 2006; 24: 953-60.

29. Isaacson PG, Matutes E, Burke M, Catovsky D. The histopathology of splenic lymphoma with villous lymphocytes. Blood 1994; 84: 3828-34.

30. Hermine O, Lefrere F, Bronowicki JP, Mariette X, Jondeau K, Eclache-Saudreau V, et al. Regression of splenic lymphoma with villous lymphocytes after treatment of hepatitis $\mathrm{C}$ virus infection. $\mathrm{N}$ Engl J Med 2002; 347: 89-94.
31. Saadoun D, Suárez F, Lefrere F, Valensi F, Mariette X, Aouba A, et al. Splenic lymphoma with villous lymphocytes, associated with type II cryoglobulinemia and HCV infection: A new entity? Blood 2005; 105: 74-6.

32. Turner NC, Dusheiko G, Jones A. Hepatitis C and B-cell lymphoma Ann Oncol 2003; 14: 1341-5.

33. Mazzaro C, Spina M, Tirelli U. Regression of low-grade non-Hodgkin's lymphoma after treatment with pegylated interferon plus ribavirin in hepatitis C virus infection. J Clin Oncol 2005; 23: 4470-1.

34. Kelaidi C, Rollot F, Park S, Tulliez M, Christoforov B, Calmus Y, et al. Response to antiviral treatment in hepatitis $\mathrm{C}$ virus-associated marginal zone lymphomas. Leukemia 2004; 18: 1711-6.

35. Armor JF, Fazili J, Toubia N, Kern W, Kamble R, Kharfan-Dabaja MA. Remission of natural-killer cell lymphoma of the liver with antihepatitis C therapy. Am J Hematol 2005; 78: 212-5.

36. Svoboda J, Andreadis C, Downs LH, Miller WT Jr, Tsai DE, Schuster SJ. Regression of advanced non-splenic marginal zone lymphoma after treatment of hepatitis C virus infection. Leuk Lymphoma 2005; 46: $1365-8$

37. Vallisa D, Bernuzzi P, Arcaini L, Sacchi S, Callea V, Marasca R, et al. Role of anti-hepatitis C virus (HCV) treatment in HCV-related, low-grade, B-cell, non-Hodgkin's lymphoma: A multicenter Italian experience. J Clin Oncol 2005; 23: 468-73.

38. Ramos-Casals M, Trejo O, García-Carrasco M, Cervera R, de la Red $\mathrm{G}$, Gil V, et al. Triple association between hepatitis $\mathrm{C}$ virus infection, systemic autoimmune diseases, and B cell lymphoma. J Rheumatol 2004; 31: 495-9.

39. Tomita N, Kodama F, Takabayashi M, Kawano T, Yamaji S, Fujimaki K, et al. Clinical features and outcome in HCV-positive aggressive non-Hodgkin's lymphoma. Leuk Lymphoma 2003; 44: 1159-64.

40. Visco C, Arcaini L, Brusamolino E, Burcheri S, Ambrosetti A, Merli $\mathrm{M}$, et al. Distinctive natural history in hepatitis $\mathrm{C}$ virus positive diffuse large B-cell lymphoma: Analysis of 156 patients from Northern Italy. Ann Oncol 2006; 17: 1434-40. 